\title{
Review: Senyawa Bahan Alam Terestrial dengan Aktivitas Antimalaria
}

\section{Jefry Presson ${ }^{\mathrm{a}}$}

${ }^{a}$ Program Studi Kimia, Universitas Timor, Kefamenanu, TTU - NTT, Indonesia, email: pressontimor@gmail.com

\section{Article Info}

Article history:

Received 23 Oktober 2018

Received in revised form 28 November 2018 Accepted 28 November 2018

DOI:

https://doi.org/10.32938/slk.v1i2.453

Keywords:

Antimalaria

Plasmodium falciparum

Terrestrial

Senyawa bahan alam

\begin{abstract}
Abstrak
Malaria masih merupakan masalah kesehatan yang sangat membutuhkan penanganan baru karena perkembangan resistensi Plasmodium falciparum. Parasit yang bertanggung jawab terhadap penyakit malaria ini terus berkembang dengan menigkatnya prevalensi. Berdasarkan World Malarial Report tahun 2015 oleh WHO, terdapat 214 juta kasus penyakit malaria dan 438.000 diantaranya meninggal dunia. Penghentian penggunaan artemisinin karena resistensi di Asia Tenggara juga merupakan masalah yang urgen. Hal ini mengindikasikan bahwa pencarian senyawa obat antimalaria yang baru merupakan suatu kebutuhan di saat ini. Eksplorasi senyawa bahan alam terestria terkait aktivitas antimalaria dalam beberapa dekade sudah banyak dilakukan dan dipublikasikan. Ulasan ini menyajikan berbagai data penelitian terbaru dan kemajuan perkembangan dalam penemuan senyawa obat dari sumber bahan alam terestrial. Senyawa antimalaria dapat ditemukan dari sumber alam bukan laut (terrestrial), seperti senyawa antimalaria dari berbagai golongan senyawa seperti alkaloid, terpena, kuasinoid, flavonoid, limonoid, kalkon, peptida, xanton, kuinon dan kumarin. Alkaloid merupakan kelas senyawa bahan alam yang terkenal sejak zaman dahulu. Alkaloid memiliki situs basa nitrogen aktif yang berasal dari prekursor biogenetik. flavonoid dapat menghambat PfENR secara reversibel dengan EGCG (35) yang menunjukkan aktivitas terbaik ( $\mathrm{Ki}=79 \pm 2,67 \mathrm{nM})$, Dua kuasinoid yang memiliki aktivitas antimalaria adalah ailanthone $\left(36, \mathrm{IC}_{50}=0,003 \mu \mathrm{g} / \mathrm{mL}\right)$ dan $6 \alpha$-tigloyloxychaparrinone $\left(37, \mathrm{IC}_{50}=0,061 \mu \mathrm{g} / \mathrm{mL}\right)$.
\end{abstract}

\section{Pendahuluan}

Malaria merupakan masalah kesehatan yang serius terutama di Asia Tenggara dan Amerika Selatan. Malaria membunuh 1-2 juta orang setiap tahun dan 300-500 juta kasus baru malaria dilaporkan setiap tahun (Snow $d k k ., 2005$ ) Hal ini diperburuk dengan penghapusan penggunaan artemisinin yang merupakan obat antimalaria komersil selama 20 tahun terakhir, karena artemisinin telah resisten di Asia Tenggara (Anonim, 2016). Malaria merupakan penyakit yang disebabkan oleh parasit protozoa dari genus Plasmodium melalui gigitan nyamuk Anopheles betina. Terdapat 5 spesies Plasmodium yang menyebabkan penyakit malaria pada manusia, namun infeksi oleh Plasmodium falciparum dan Plasmodium vivax adalah yang paling umum terjadi. Perkembangan resistensi terhadap obat-obatan komersil seperti klorokuin, artemisinin dan analog artemisinin menciptakan kebutuhan mendesak untuk menemukan senyawa antimalaria baru.

Pada tahun 1972, Tu Youyou, seorang ilmuwan asal Cina mengisolasi artemisinin, suatu seskuiterpen lakton dengan jembatan peroksida yang tidak biasa dari tumbuhan Artemisia anпиa. Senyawa ini terbukti dapat melawan parasit malaria yang telah resisten terhadap klorokuin (Klayman, 1985) Perkembangan turunan artemisinin telah menjadi kemajuan besar dalam kemoterapi malaria. Namun, derivatif artemisinin masih memiliki keterbatasan. Keterbatasan pertama adalah artemisinin derivatif gagal membunuh semua parasit di dalam darah, sehingga parasit muncul kembali di dalam darah dan penyakit kembali berulang (Wright, 2005). Untuk mengatasi masalah ini WHO merekomendasikan pengobatan dengan artemisinin derivatif harus diikuti oleh obat antimalaria kedua untuk membersihkan sisa parasit (Wilairatana $d k k$. 2002). Keterbatasan kedua adalah bahwa dibandingkan dengan klorokuin artemisinin derivatif relatif mahal apalagi harus diikuti dengan penggunaan obat antimalaria kedua

Alam merupakan sumber yang terus berevolusi untuk kepentingan senyawa obat. Penggunaan tanaman obat untuk pengobatan penyakit malaria hingga kini sudah banyak dikenal. Ulasan ini berfokus pada senyawa antimalaria yang ditemukan dari sumber alam bukan laut (terrestrial). Ulasan ini mencakup senyawa antimalaria dari berbagai golongan senyawa seperti alkaloid, terpena kuasinoid, flavonoid, limonoid, kalkon, peptida, xanton, kuinon dan kumarin.

\section{Alkaloid}

Alkaloid merupakan kelas senyawa bahan alam yang terkenal sejak zaman dahulu. Alkaloid memiliki situs basa nitrogen aktif yang berasal dari prekursor biogenetik.
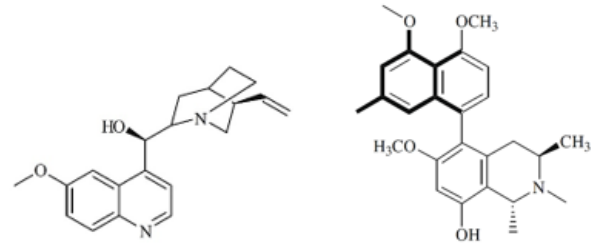

1. Quinine

2. Ancistrocongoline- $B$
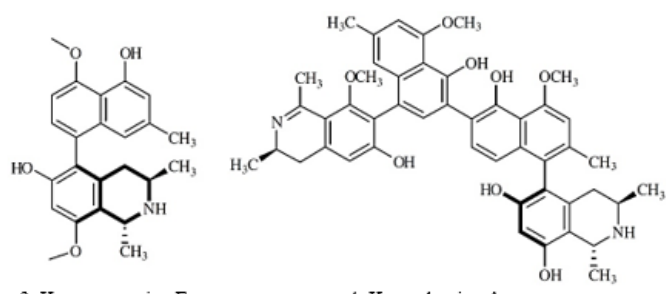

3. Korupensamine $\mathrm{E}$

4. Korundamine A

Gambar 1. Senyawa Antimalaria Kelompok Alkaloid
Salah satu contoh senyawa antimalaria dikelas ini adalah quinine (1, Gambar) dari Cinchona succirubra (Rubiaceae) yang telah digunakan untuk pengobatan malaria selama lebih dari tiga abad. Senyawa antimalaria berbasis alkaloid meliputi naphthylisoquinolines, bisbenzylisoquinolines, indoldanmanzamin.

Kelompok senyawa naphthylisoquinolines meliputi senyawa-senyawa berikut ini. KorupensamineE (3) (suatu alkaloid monomerik) (Hallock $d k k$. 1997)dan korundamine A (4) (suatu alkaloid heterodimerik) (Hallock dkk., 1998) memiliki aktivitas antimalaria melawan $P$. Falciparum, dengan nilai $\mathrm{IC}_{50}$ secara berurutan $2,0 \mu \mathrm{g} / \mathrm{mL}$ dan $1,1 \mu \mathrm{g} / \mathrm{mL}$. Kedua senyawa ini diekstrak dari Ancistrocladus korupensis. Hubungan struktur-aktivitas secara komputasi menunjukkan bahwa kehadiran amina sekunder dan ketiadaan substituen oksigen pada C-6, dan konfigurasi - (R) pada C-3 memegang peranan penting terhadap aktivitas antimalaria. Bringmann $d k k$. melaporkan ancistrocongolines $A-D$ dan korupensamine A dari Ancistrocladus congolensis. Semua senyawa ini menunjukkan aktivitas antiplasmodial dengan ancistrocongoline- $B$ (2) yang paling aktif $\left(\mathrm{IC}_{50}=0,15 \mu \mathrm{g} / \mathrm{mL}\right)$ (Bringmann $d k k$. , 2000a). Semua ancistrocongolines dan Korupensamine A adalah perwakilan 'tipe hibrida' dari kelompok senyawa naphthoisoquinolines.

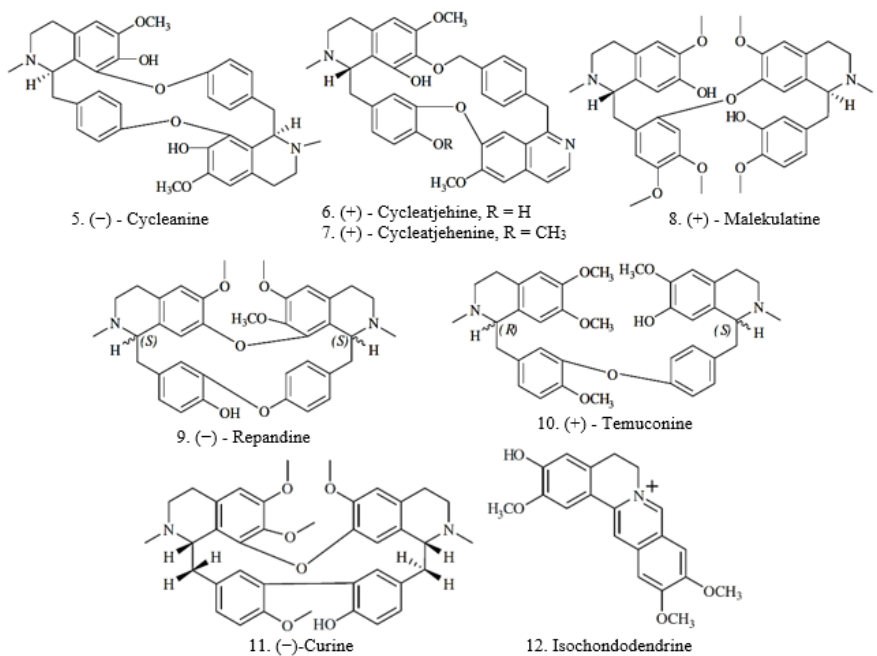

Gambar 2. Senyawa Antimalaria Kelompok Alkaloid Bisbenzilisoquinoline

Kelompok alkaloid Bisbenzilisoquinolinemerupakan alkaloid dengan jembatan diaril eter. Kelompok senyawa ini dapat dibagi menjadi tiga kategori: biskoklaurin, koklaurin-retikulindanbisretikulin, berdasarkan nomor rantai jembatan. Angerhofer $d k k$. menguji 53 alkaloid bisbenzylisoquinoline untuk aktivitas antiplasmodial dan sitotoksisitas terhadap sel mamalia (Angerhofer $d k k$., 1999). Senyawa-senyawa tersebut menunjukkan aktivitas antiplasmodial dengan nilai $\mathrm{IC}_{50}$ berkisar antara $29-1500 \mathrm{nM}$ terhadap klon D6, dan $\mathrm{IC}_{50}$ berkisar antara 59-4030 nM melawan klon W2 P. falciparum). Alkaloid paling selektif adalah $(-)$ - cycleanine $(5),(+)$ - cycleatjehine $(6),(+)$ - cycleatjehenine $(7),(+)$ - malekulatine $(8),(-)$ - repandine $(9)$ dan $(+)$ - temuconine $(10)$. Pada beberapa senyawa-senyawa tersebut, $(+)$ - malekulatine merupakan turunan bisretikulin, sementara yang lainnya adalah biskoklaurin. Mambu $d k k$. melaporkan aktivitas antiplasmodial yang kuat dari senyawa (-)-curine (11) and isochondodendrine (12) yang diisolasi dari kulit batang Isolona ghesquiereina $\left(\mathrm{IC}_{50}=353\right.$ dan 892 nM, secara berurutan) (Mambu $d k k$., 2000).

Kelompok alkaloid lainnya adalah indol. Paulo $d k k$. menguji ekstrak etanol dan air dari Cryptolepis sanguinolenta terhadap strain K1 dan T996 $P$. falciparum. Hasil uji menunjukkan bahwa alkaloid indolobenzazepin: 
cryptoheptine (13) merupakan senyawa paling aktif setelah cryptolepine (14) $\left(\mathrm{IC}_{50}=0,8\right.$ dan $0,23 \mu \mathrm{M}$, secara berurutan) (Paulo $d k k$.,2000). Senyawa lainnya dalam kelompok alkaloid indol adalah alkaloid dimer dan trimer indolomonoterpen yang diisolasi dari kulit akar Strychnos icaja asal Afrika Tengah.

Frederich $d k k$. melaporkan bahwa sungusin memiliki aktivitas antimalaria yang menarik. Modifikasi ikatan rangkap dari 23'-17' menjadi 16'-17 dan pemasukan substituen hidroksi pada C-18 dapat menigkatkan aktivitas antimalaria, seperti 18-hidroxyisosungucine (18) $\left(\left(\mathrm{IC}_{50}=0,14 \mu \mathrm{M}\right.\right.$, melawan strain W2). Pengujian in vitro terhadap P.falciparum yang resisten klorokuin menunjukan bahwa strychnogucine $B$ (19) lebih aktif dari sungucine $(20)\left(\mathrm{IC}_{50}=\right.$ 0,085 dan $10 \mu \mathrm{M}$, secara berurutan) (Frederich $d k k ., 2000$ ).

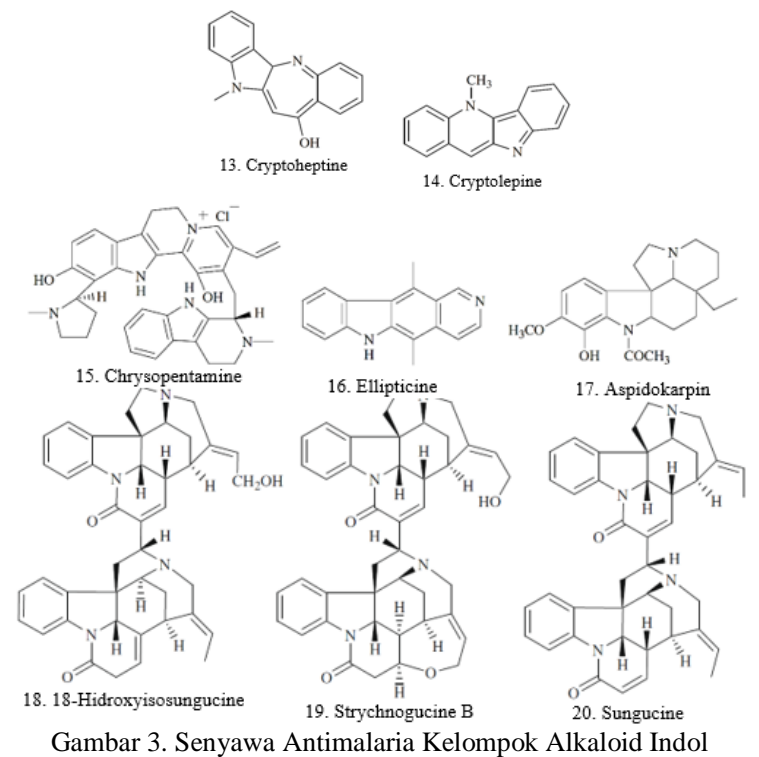

Senyawa kelompok alkaloid indol lainnya adalah chrysopentamine (15) yang diisolasi dari S. usambarensis sebuah alkaloid indolomonoterpenoid dengan 5 atom nitrogen dan cincin pyridinium (Frédérich dkk., 2004) Chrysopentamine (15) menunjukkan aktivitas antiplasmodial melawan 3 sel $P$. falciparum: FCA 20, FCB1-R dan W2 $\left(\mathrm{IC}_{50}=500 \mathrm{nM}\right)$. Senyawa ellipticine $(16)$ dan aspidokarpin (17) diisolasi dari Aspidosperma vargasii dan A. desmanthum, menunjukkan inhibisi in vitro yang signifikan terhadap strain $P$. falciparum $\mathrm{K} 1$, $\left(\mathrm{IC}_{50}=73\right.$ dan $19 \mathrm{nM}$, secara berurutan) (Silva $\left.d k k ., 2013\right)$

\section{Flavonoid}

Mekanisme senyawa flavonoid terhadap aktivitas antimalaria belum diketahui secara jelas, namun beberapa flavonoid terbukti menghambat masuknya L-glutamine dan myoinositol menjadi erythrocytes (Elford, 1986). Senyawa Exiguaflavanone A (21)dan exiguaflavanone $B$ (22) dari tumbuhan Artemisia indica menunjukkan aktivitas antiplasmodial secara in vitro $\left(\mathrm{IC}_{50}=4,6\right.$ dan 7,0 $\mu \mathrm{g} / \mathrm{mL}$, secara berurutan) (Chanphen $d k k$., 1998). Senyawa (-) - cis-3Acetoxy-4',5,7-trihydroxyflavanone $\left(23, \mathrm{IC}_{50}=24,3 \mu \mathrm{g} / \mathrm{mL}\right)$ diisolasi dari ekstrak lipofilik daun Siparuna andina aktivitas antimalaria secara in vitro yang lebih tinggi $\left(\mathrm{IC}_{50}=3,0 \mu \mathrm{g} / \mathrm{mL}\right)$ (Jenett-Siems $d k k$., 2000). Meskipun begitu senyawa 23 kurang aktif dibanding 6-hydroxyluteolin-7-O- (1'-a-rhamnoside $\left(24, \mathrm{IC}_{50}=2,13\right.$ dan 3,32 $\mu \mathrm{M}$ terhadap strain K1 dan NF54, secara berurutan) yang diperoleh dari Vriesea sanguinolenta, (Bringmann $d k k$., 2000b).

Senyawa isoflavon calycosin (25) dan genistein (26) yang diisolasi dar Andira inermis merupakan senyawa isoflavon pertama yang dilaporkan memiliki aktivitas antiplasmodial $\left(\mathrm{IC}_{50}=4,2\right.$ dan $9,8 \mu \mathrm{g} / \mathrm{mL}$ untuk calycosin, dan $\mathrm{IC}_{50}=$ 2,0 dan $4,1 \mu \mathrm{g} / \mathrm{mL}$ untuk genistein, melawan strain poW dan Dd2, secara berurutan) (Kraft $d k k$., 2000). Aktivitas antiplasmodial dari isoflavanquinon dilaporkan untuk pertama kalinya oleh Kittakoop $d k k$. melalui isolasi abruquinone $B$ (27), $\mathrm{IC}_{50}=1,5 \mu \mathrm{g} / \mathrm{mL}$ ) dari Abrus precatorius (Limmatvapirat $d k k$., 2004).Senyawa flavonoid lainnya yang memiliki aktivitas antiplasmodial adalah arabinofuranosides (28) yang diperoleh dari daun Calycolpus warszewiczianus dengan nilai $\mathrm{IC}_{50}=14,5 \mu \mathrm{M}$ (Torres-Mendoza $d k k$., 2006). Studi SAR menunjukkan bahwa bagian galloyl meningkatkan aktivitas antimalaria, sementara kelompok asetat menurunkan aktivitas antimalaria. Glikosida flavon (29) dari Phlomis brunneogaleata (Kirmizibekmez dkk., 2004) dan iridoid (30) dari Scrophularia lepidota (Tasdemir $d k k ., 2005$ ) telah dilaporkan menghambat enzim FabI $P$. falciparum ( $\mathrm{IC}_{50}=10$ dan $100 \mu \mathrm{g} / \mathrm{mL}$, secara berurutan). Banyak biflavon telah dilaporkan memiliki aktivitas antimalaria sedang hingga tinggi sikokianin $\mathrm{B}$ dan $\mathrm{C}$ ( 31 dan $32, \mathrm{IC}_{50}=0,54$ dan $0,56 \mu \mathrm{g} / \mathrm{mL}$, secara berurutan) dari Wikstroemia indica (Nunome $d k k ., 2004)$. Senyawa $33\left(\mathrm{IC}_{50}=80,0 \mathrm{ng} / \mathrm{mL}\right.$ ) diisolasi dari Ochna integerrima (Ichino dkk., 2006) dan senyawa $34\left(\mathrm{IC}_{50}=6,7\right.$ $\mu \mathrm{M}$ ) dari Garcinia livingstonei (Mbwambo dkk., 2006). Senyawa 33 tersebut lebih aktif 10 kali lipat daripada sikokianin B dan C. Ekstrak teh hijau mengandung berbagai metabolit sekunder terutama flavonoid, salah satunya adalah katekin seperti: (-) epigallocatechin gallate (EGCG), (-) -epicatechin gallate, $(-)$ - epigallocatechin, dan $(-)$ - epicatechin. Surolia dkk. menunjukkan bahwa flavonoid tersebut dapat menghambat PfENR secara reversibel dengan EGCG (35) yang menunjukkan aktivitas terbaik ( $\mathrm{Ki}=79 \pm 2,67 \mathrm{nM})$ (Sharma dkk., 2007).

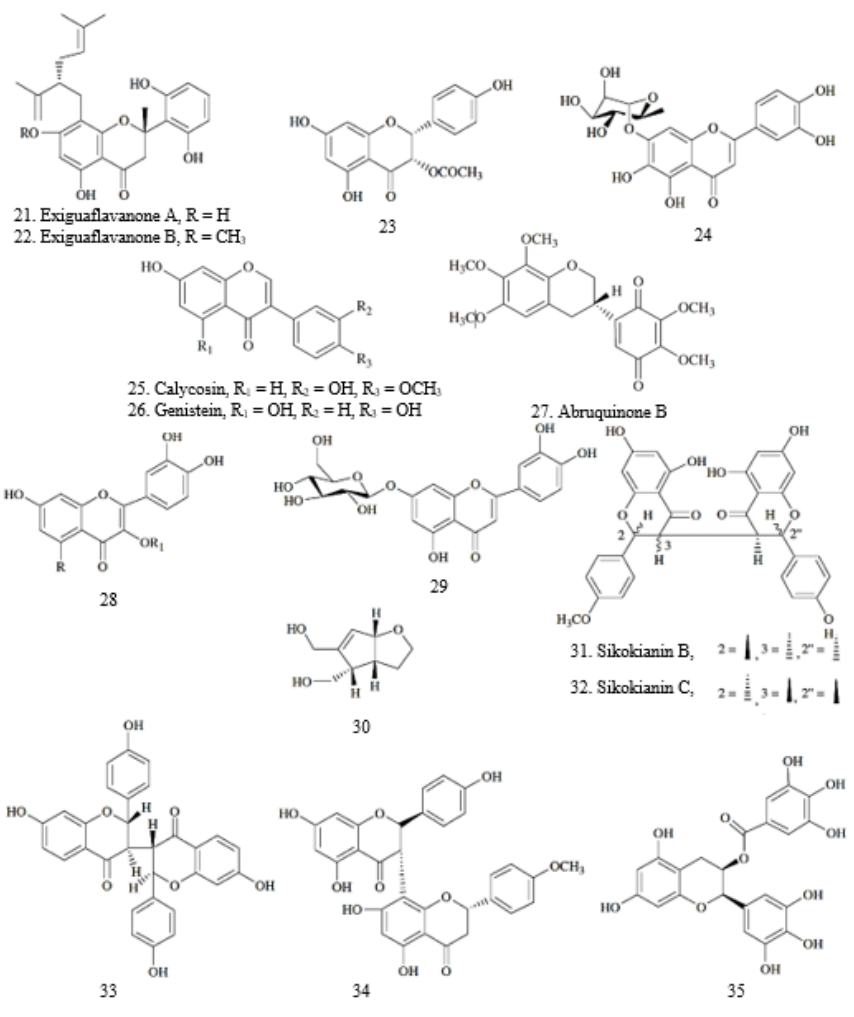

Gambar 4. Senyawa Antimalaria Kelompok Flavonoid

\section{Kuasinoid}

Kuasinoid adalah kelompok triterpen terdegradasi yang ditemukan pada famili Simaroubaceae. Kebanyakan kuasinoid yang diisolasi memiliki kerangka C-20 dan $\delta$-lakton, sedangkan tipe kerangka C-19 adalah $\gamma$-lakton. Dua kuasinoid yang memiliki aktivitas antimalaria adalah ailanthone $\left(36, \mathrm{IC}_{50}=0,003 \mu \mathrm{g} / \mathrm{mL}\right)$ dan $6 \alpha$-tigloyloxychaparrinone $\left(37, \mathrm{IC}_{50}=0,061 \mu \mathrm{g} / \mathrm{mL}\right)$ yang diisolasi dari Ailanthus altissima (Okunade dkk., 2003). Kuasinoid seperti pasakbumin B (38), pasakbumin C (39) dan eurycomanone (40) juga memiliki aktivitas antimalaria yang diisolasi dari E. Longifolia $\left(\mathrm{IC}_{50}=22,6 ; 93,3\right.$ dan $40,0 \mathrm{ng} / \mathrm{mL}$, secara berurutan) (Kuo dkk., 2004). Simalikalactone D (41) dan orinocinolide (42) yang diisolasi dari akar Simaba orinocensis, sama-sama kuat melawan strain D6 (IC 5 = 3,0 dan 3,67 ng/mL, secara berurutan) dan strain $\mathrm{W} 2\left(\mathrm{IC}_{50}=3,2 \mathrm{dan} 8,5 \mathrm{ng} / \mathrm{mL}\right.$, secara berurutan) (Muhammad $d k k$., 2004). Senyawa-senyawa ini menghambat biosintesis protein pada sistem translasi dari sel-sel Krebs, secara in vitro deAndrade-Neto $d k k$. telah melaporkan neosergeolide (43) yang diisolasi dari Picrolemma sprucei, menunjukkan aktivitas antimalaria yang kuat $\left(\mathrm{IC}_{50}=2.0\right.$ nM) (Silva $d k k ., 2013)$. Beberapa persyaratan struktural, seperti kehadiran $\alpha, \beta$ keton tak jenuh dalam cincin $\mathrm{A}$, jembatan epoksimetilen dalam cincin $\mathrm{C}$ dan fungsi ester dalam C-15 dianggap sebagai penentu aktivitas antimalaria.

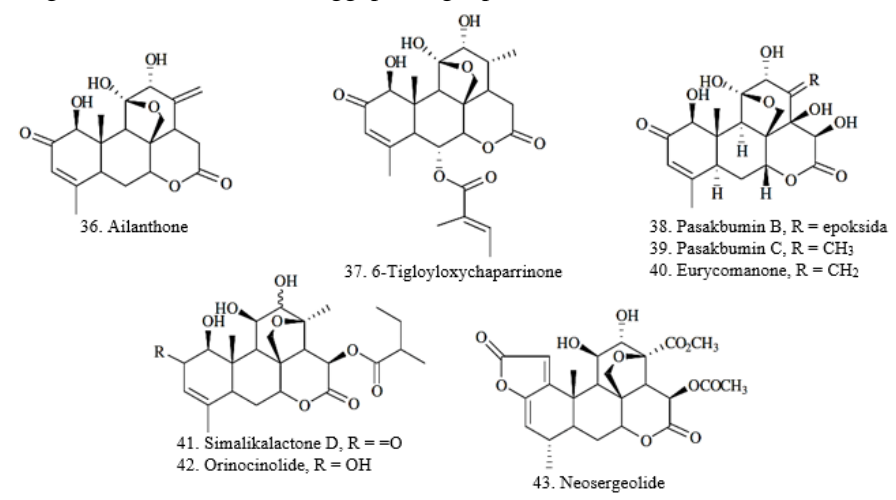

Gambar 5. Senyawa Antimalaria Kelompok Kuasinoid

\section{Limonoid}

Limonoid diproduksi oleh famili Meliaceae. Salah sartu contoh adalah Azadirachta indica (lebih dikenal dengan Neem Tree), banyak digunakan sebagai tanaman antiplasmodial di Asia. Rochanakij $d k k$. mengidentifikasi bahwa nimbolide dari Neem Tree memilki aktivitas antiplasmodial $\left(\mathrm{EC}_{50}=0,95 \mathrm{ng} / \mathrm{mL}\right.$ melawan P. falciparum K1) (Rochanakij $d k k$., 1985).Beberapa tumbuhan seperti Cedrela odorata (Bray dkk., 1990), Khaya senegalensis dan Khaya grandifoliola (Bickii $d k k ., 2000)$ pernah dilaporkan mengandung limonoid dengan aktivitas antimalaria secara in vitro. Dua limonoid, trichirubine $A$ (44) dan trichirubine $B$ 
(45) telah diisolasi dari T. rubescens dengan aktivitas antimalaria yang signifikan $\left(\mathrm{IC}_{50}=0,3\right.$ dan $0,2 \mu \mathrm{g} / \mathrm{mL}$, secara berurutan) (Krief $d k k$., 2004). Turunan limonoid 7-deacetylgedunin (46) dan 7-deacetyl-7-oxogedunin (47) yang diisolasi dari akar Pseudocedrela kotschyi telah dilaporkan memiliki aktivitas antimalaria $\left(\mathrm{IC}_{50}=1,36\right.$ dan $1,77 \mu \mathrm{g} / \mathrm{mL}$, secara berurutan) (Hay $\left.d k k ., 2007\right)$.
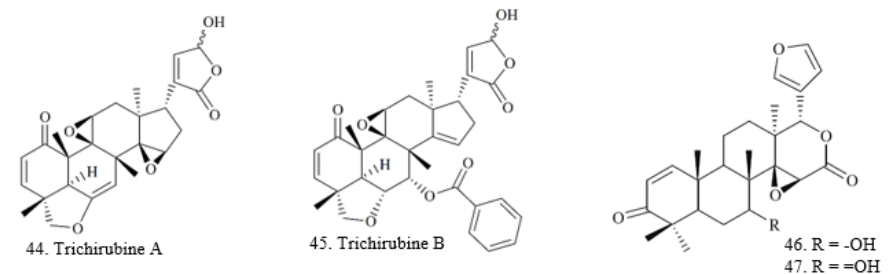

Gambar 6. Senyawa Antimalaria Kelompok Limonoid

\section{Kalkon}

Senyawa Licochalcone A (48) yang diisolasi dari Glycyrrhiza inflata telah teridentifikasi memiliki potensi sebagai inhibitor protein dari Plasmodium (Chen dkk., 1994). Senyawa(+)-Nyasol $\left(49, \mathrm{IC}_{50}=49 \mu \mathrm{M}\right)$ diisolasi dari Asparagus africanus (Oketch-Rabah dkk., 1997). Senyawa 5-Prenylbutein $\left(50, \mathrm{IC}_{50}=10,3\right.$ $\mu \mathrm{M})$ dari Erythrina abyssinica,juga pernah dilaporkan memiliki aktivitas antimalaria. Boyom dkk. mengisolasi bartericin A (51), stipulin (52)dan4hydroxylonchocarpin (53) dari Dorstenia barteri var. subtriangularis. Senyawa 51-53 aktif secara in vitro melawan P. Falciparum $\left(\mathrm{IC}_{50}=2,15 ; 5,13\right.$ dan 3,36 $\mu \mathrm{M}$, secara berurutan) (Yenesew $d k k$., 2004).

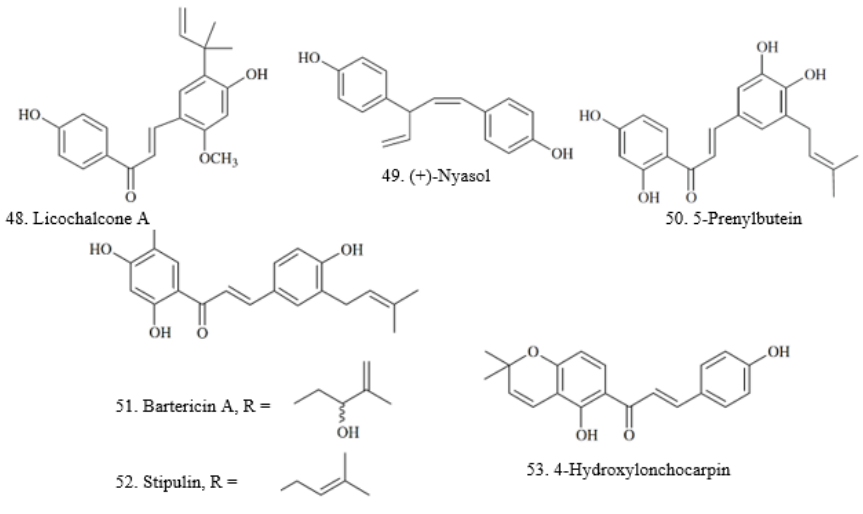

Gambar 7. Senyawa Antimalaria Kelompok Kalkon

\section{Peptida}

Senyawa apicidin (54) termasuk kelompok tetrapeptida siklik (CTP) yang langka yang diisolasi dari fungi Fusarium pallidoroseum. Apicidin menghambat histon deasetilase protozoa (HAD) pada skala nanomolar dan aktif melawan $P$. berghei pada tikus (Darkin-Rattray $d k k$., 1996).Senyawa peptida antimikroba pernah diisolasi dari kulit katak seperti dermaseptin S4 (ALWMTLLKKVLKAAAKAALNAVLVGANA) dan dermaseptin S3 (ALWKNMLKGIGKLAGKAALGAVKKLVGAES). Ghosh $d k k$. melaporkan bahwa peptida dermaseptin S4 dan dermaseptin S3 menghambat kemampuan parasit untuk memasukkan hypoxanthine (Ghosh dkk., 1997).Senyawa beauvericin (55) dan beauvericin A (56) (kelompok cyclodepsipeptides) yang diisolasi dari jamur Paecilomyces tenuipes BCC 1614, menunjukkan aktivitas antiplasmodial moderat terhadap strain $\mathrm{K} 1(\mathrm{EC} 50=1,60$ dan $12,0 \mu \mathrm{g} / \mathrm{mL}$, masing-masing) (Nilanonta $d k k$., 2000). Tetrapeptida linear yang diisolasi dari jamur entomopatogenik Hirsutella sp. BCC 1528, menunjukkan aktivitas melawan P. falciparum $\mathrm{K} 1\left(\mathrm{IC}_{50}=8,0 \mu \mathrm{M}\right)$.
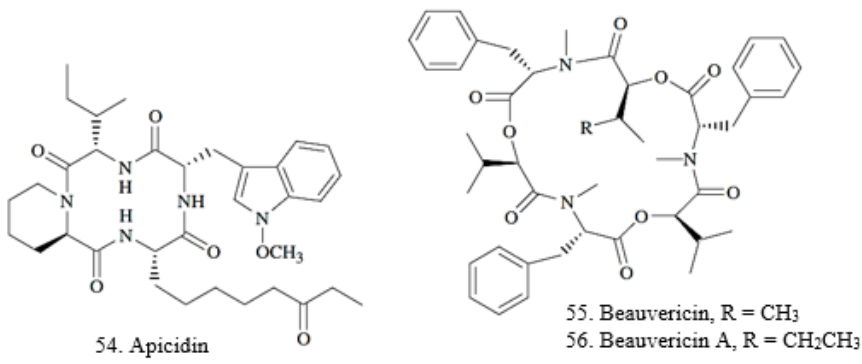

Gambar 8. Senyawa Antimalaria Kelompok Peptida

\section{Kumarin, Xanton dan Kuinon}

Kulit batang Exostema mexicanum digunakan sebagai pengganti kuinin untuk pengobatan malaria di Amerika Latin. Ekstrak lipofilik senyawa $O$ methylexostemin (68) menunjukkan aktivitas antiplasmodial yang sangat kuat $\left(\mathrm{IC}_{50}=3,60 \mu \mathrm{g} / \mathrm{mL}\right)$ (Köhler $d k k$., 2001). Ekstrak EtOAc dari kulit batang Hintonia latiflora menunjukkan aktivitas antimalaria terhadap P.berghe schizonts secara invitro dengan senyawa phenylcoumarins 69 dan $70\left(\mathrm{IC}_{50}=24,7\right.$ dan 25,9 $\mu \mathrm{M}$, secara berurutan) (Argotte-Ramos $d k k$., 2006).

Garcinia cowa melaporkan beberapa senyawa xanton dengan aktivitas antiplasmodial seperti, cowaxanthone $\left(57, \quad \mathrm{IC}_{50}=1,50 \mu \mathrm{g} / \mathrm{mL}\right)$, kalothwaitesixanthone $\left(58, \mathrm{IC}_{50}=2,7 \mu \mathrm{g} / \mathrm{mL}\right)$, dan mangostin $\left(59, \mathrm{IC}_{50}=17,0\right.$ $\mu \mathrm{M}$ ), yang diisolasi dari Calophyllum caledonicum dan Garcinia mangostana (Likhitwitayawuid $d k k$., 1998)

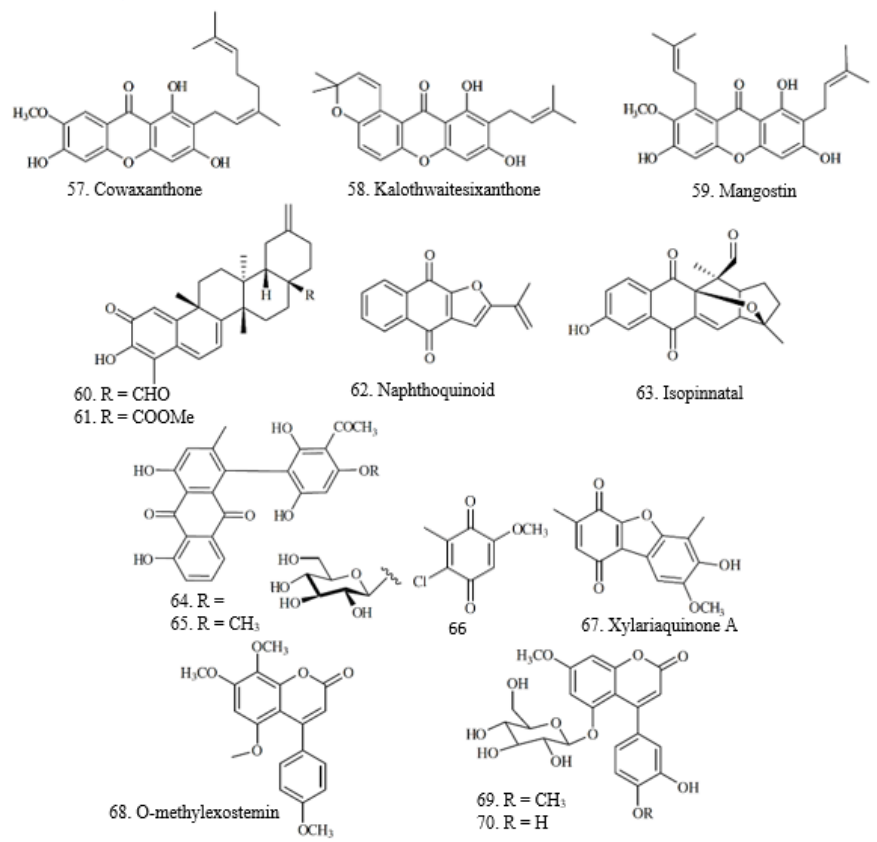

Gambar 9. Senyawa Antimalaria Kelompok Kumarin, Xanton dan Kuinon

Senyawa kuinon 60 dan 61 diisolasi dari akar Salacia kraussii. Isolat menunjukkan aktivitas antiplasmodial yang tinggi dengan nilai $\mathrm{IC}_{50}=94,0$ dan $27,6 \mathrm{ng} / \mathrm{mL}$, secara berurutan (Figueiredo $d k k$., 1998). Senyawa naphthoquinoid (62) dan isopinnatal (63) dari Kigelia pinnata dilaporkan memiliki aktivitas antimalaria yang baik $\left(\mathrm{IC}_{50}=0,15\right.$ dan $0,25 \mu \mathrm{M}$, secara berurutan). Senyawa phenylanthraquinones (64) dan knipholone (65) diisolasi dari Bulbine frutescens, menunjukkan aktivitas antiplasmodial dengan nilai $\left(\mathrm{IC}_{50}=0,67\right.$ dan $0,41 \mu \mathrm{g} / \mathrm{mL}$ secara berurutan. Metabolit benzoquinone 66 dan 67 dari jamur endofit Xylaria sp152 telah dilaporkan memiliki aktivitas antimalaria $\left(\mathrm{IC}_{50}=1,84\right.$ dan $6,68 \mu \mathrm{M}$ secara berurutan) (Tansuwan $d k k ., 2007)$.

\section{Terpena}

\subsection{Seskuiterpena}

Lakton sesquiterpene dari Neurolaena lobata telah dilaporkan memiliki aktivitas antimalaria (François dkk., 1996). Senyawa germacranolide sesquiterpenes, seperti neurolenin $\mathrm{B}\left(71, \mathrm{IC}_{50}=0,62 \mu \mathrm{M}\right)$ dilaporkan lebih kuat dari lobatin $\mathrm{B}\left(72, \mathrm{IC}_{50}=16,51 \mu \mathrm{M}\right)$. Pada senyawa kelompok germacranolides pergeseran ikatan rangkap dari posisi -2,3 (neurolenin B) ke posisi -3,4 (lobatin A) menyebabkan penurunan aktivitas antimalaria. Hal ini menunjukkan bahwa kehadiran $\alpha / \beta$-keto tak jenuh sangat penting. Selain itu, gugus hidroksil bebas pada C-8 meningkatkan aktivitas antiplasmodial, sementara gugus hidroksi bebas pada C-9 menurunkan aktivitas antiplasmodial. Beberapa senyawa antimalaria bekerja dengan cara menghambat degradasi hemin, agar hemin bebas dapat membunuh parasit malaria. Beberapa sesquiterpen, misalnya senyawa 100 dari ekstrak EtOAc dari daun Melampodium camphoratum telah dilaporkan menunjukkan aktivitas pada uji degradasi hemin.

Tiga lakton seskuiterpena yang diperoleh dari Anthemis auriculata, yaitu anthecotulide (73), 4-hydroxyanthecotulide (74) dan 4-acetoxyanthecotulide (75) telah dievaluasi. Evaluasi tersebut melihat efek penghambatan terhadap enzim FabI dari tiga mikroorganisme patogen, yaitu P. falciparum (PfFabI), Mycobacterium tuberculosis (MtFabI) dan Escherichia coli (EcFabI), serta 2 enzim elongasi dari sistem FAS-II plasmodial, b-ketoacyl-ACP reduktase (PfFabG) dan b-hydroxyacyl-ACP deydratase (PfFabZ). Senyawa menunjukkan diferensiasi yang jelas dalam penghambatan enzim FabI. Turunan oksigen (74 dan 75) secara khusus menghambat enzim FAS-II plasmodial, PfFabIdan PfFabG $\left(\mathrm{IC}_{50}=20-75 \mu \mathrm{g} / \mathrm{mL}\right)$. Senyawa 73 sangat lemah menghambat PfFabI (Karioti $d k k ., 2008$ )

\subsection{Diterpena}

Tiga lakton diterpena yang diisolasi dari Parinari capensis yaitu senyawa 76,77 , dan 78 menunjukkan aktivitas antimalaria yang menjanjikan $\left(\mathrm{IC}_{50}=0,54\right.$ 0,67 , dan $1,57 \mu \mathrm{g} / \mathrm{mL}$, secara berurutan) (Uys $d k k$., 2002). Suatu asam diterpena tetrasiklik dari Scoparia dulcis, (-) - scopadulcic acid A (SDA, 79) telah menunjukkan aktivitas melawan $P$. falciparum $\left(\mathrm{IC}_{50}=27,0\right.$ dan 19,0 $\mu \mathrm{M}$, terhadap strain D6 dan W2, secara berurutan) (Riel $d k k$., 2002). Mekanisme aksi dari senyawa 128 adalah menghambat pompa $\mathrm{H}^{+}$-ATPase yang ada pada membran plasma dan vakuola makanan dari parasit. 
Investigasi fitokimia terhadap biji Aframomum zambesiacum melaporkan 5 diterpenoid labdane. Senyawa-senyawa tersebut terbukti dapat melawan strain FCB1 resisten-CQ. Senyawa yang memiliki aktivitas antiplasmodial tinggi terhadap uji ini adalah senyawa yang paling polar (80) dengan nilai $\mathrm{IC}_{50}=4,97$ $\mu \mathrm{M}$ (Kenmogne $d k k$., 2006). Isolasi tujuh diterpenoid baru dari daun Nuxia sphaerocephala, termasuk clerodane (81) dan derivatif labdane (82) menunjukkan aktivitas penghambatan $\left(\mathrm{IC}_{50}=4,3-21,0 \mu \mathrm{g} / \mathrm{mL}\right)(\mathrm{Mambu} d k k$. 2006)

\subsection{Triterpena}

Fanta $d k k$. melaporkan aktivitas antiplasmodial dari 2 triterpenoid saponin, glinosida A (83) dan glinosida B (84) yang diisolasi dari Glinus oppositifolius (Traore dkk., 2000). Ekstrak mentah menunjukkan aktivitas antiplasmodial yang lebih baik $\left(\mathrm{IC}_{50}=31,8 \mu \mathrm{g} / \mathrm{mL}\right)$ dibandingkan saponin murni $\left(83, \mathrm{IC}_{50}=42,3 \mu \mathrm{g} / \mathrm{mL}\right)$. Asam epi-oleanolic $\left(85, \mathrm{IC}_{50}=28,3 \mu \mathrm{M}\right)$ juga telah dilaporkan dari Celaenodendron mexicanum memiliki aktivitas antimalaria (del Rayo Camacho $d k k$., 2000). Senyawa iridal (86), sebuah triterpenoid yang diekstrak dari Iris germanica $L$. Menunjukkan nilai IC $_{50}$ berkisar antara 1,8;26,0 dan $14,0 \mu \mathrm{g} / \mathrm{mL}$ terhadap $P$. Falciparum untuk 3 kali inkubasi (masing-masing 72 jam, 48 jam dan 32 jam).

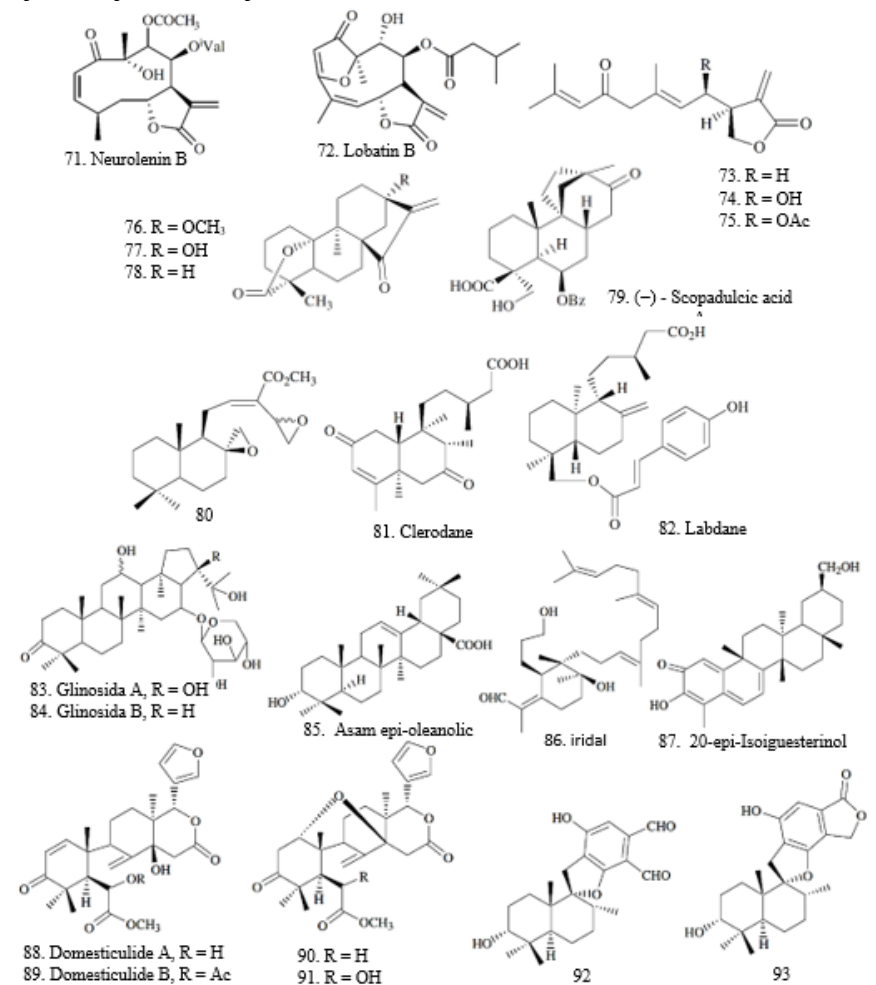

Gambar 10. Senyawa Antimalaria Kelompok Terpena

Sebuah kuinon bisnortriterpena, 20-epi-isoiguesterinol (87) diisolasi dari akar Salacia madagascariensis menunjukkan aktivitas antiplasmodial melawan $P$. Falciparum $\left(\mathrm{IC}_{50}=68 \mathrm{ng} / \mathrm{mL}\right.$ ) (Thiem $d k k$., 2005). Saewan $d k k$. melaporkan aktivitas antimalaria tetranortriterpenoid, domesticulide $A$ (88) dan domesticulide $B$ (89) serta triterpenoid $(90,91)$, diisolasi dari biji Lansium domesticum Corr (Saewan $d k k ., 2006)$. Perbandingan nilai $\mathrm{IC}_{50}$ dari triterpenoid $90\left(\mathrm{IC}_{50}=5,9\right.$ $\mu \mathrm{g} / \mathrm{mL})$ dan $91\left(\mathrm{IC}_{50}=20 \mu \mathrm{g} / \mathrm{mL}\right)$ menunjukkan bahwa penambahan hidroksil pada C-6 menurunkan aktivitas antimalaria. Pada tetranortriterpenoid, substitusi gugus acetoxyl di C-6 menghasilkan aktivitas antimalaria yang lebih tinggi (88, $\mathrm{IC}_{50}=20 \mu \mathrm{g} / \mathrm{mL}$, dan $\left.89, \mathrm{IC}_{50}=\mu \mathrm{g} / \mathrm{mL}\right)$. Aktivitas antimalaria terpena spirofuran dilaporkan untuk pertama kalinya oleh Sawadjoon (Sawadjoon $d k k$., 2004). Senyawa 92 dan 93 yang diisolasi dari jamur Stachybotrys nephrospora ini memiliki aktivitas antiplasmodial $\left(\mathrm{IC}_{50}=0,85\right.$ dan $0,15 \mu \mathrm{g} / \mathrm{mL}$, secara berurutan $)$ dan tidak toksik terhadap sel Vero. Ekstrak mentah dari Grewia bilamellata menunjukkan aktivitas antimalaria dengan nilai $\mathrm{IC}_{50}=2,2$ dan $1,7 \mu \mathrm{g} / \mathrm{mL}$, terhadap strain D6 dan W2 secara berurutan (Ma dkk., 2006).

\section{Simpulan}

Senyawa antimalaria dapat ditemukan dari sumber alam bukan lau (terrestrial), seperti senyawa antimalaria dari berbagai golongan senyawa seperti alkaloid, terpena, kuasinoid, flavonoid, limonoid, kalkon, peptida, xanton, kuinon dan kumarin. Alkaloid merupakan kelas senyawa bahan alam yang terkenal sejak zaman dahulu. Alkaloid memiliki situs basa nitrogen aktif yang berasal dari prekursor biogenetik. flavonoid dapat menghambat PfENR secara reversibel dengan EGCG (35) yang menunjukkan aktivitas terbaik (Ki $=79 \pm$ 2,67 $\mathrm{nM}$ ), Dua kuasinoid yang memiliki aktivitas antimalaria adalah ailanthone $\left(36, \mathrm{IC}_{50}=0,003 \mu \mathrm{g} / \mathrm{mL}\right)$ dan $6 \alpha$-tigloyloxychaparrinone $\left(37, \mathrm{IC}_{50}=0,061\right.$ $\mu \mathrm{g} / \mathrm{mL})$.
Pustaka

Angerhofer, C.K., Guinaudeau, H., Wongpanich, V., Pezzuto, J.M. \& Cordell, G.A. 1999. Antiplasmodial and Cytotoxic Activity of Natural Bisbenzylisoquinoline Alkaloids. Journal of Natural Products, 62(1): 5966.

Argotte-Ramos, R., Ramírez-Avila, G., Rodríguez-Gutiérrez, M. del C., OvillaMuñoz, M., Lanz-Mendoza, H., Rodríguez, M.H., González-Cortazar, M. \& Alvarez, L. 2006. Antimalarial 4-phenylcoumarins from the stem bark of Hintonia latiflora. Journal of natural products, 69(10): 1442-1444.

Bickii, J., Njifutie, N., Foyere, J.A., Basco, L.K. \& Ringwald, P. 2000. In vitro antimalarial activity of limonoids from Khaya grandifoliola CDC (Meliaceae). Journal of Ethnopharmacology, 69(1): 27-33.

Bray, D.H., Warhurst, D.C., Connolly, J.D., O’Neill, M.J. \& Phillipson, J.D. 1990. Plants as sources of antimalarial drugs. Part 7. Activity of some species of Meliaceae plants and their constituent limonoids. Phytotherapy Research, 4(1): 29-35.

Bringmann, G., Hamm, A., Günther, C., Michel, M., Brun, R. \& Mudogo, V. 2000a. Ancistroealaines A and B, two new bioactive naphthylisoquinolines, and related naphthoic acids from Ancistrocladus ealaensis. Journal of natural products, 63(11): 1465-1470.

Bringmann, G., Ochse, M., Zotz, G., Peters, K., Peters, E.-M., Brun, R. \& Schlauer, J. 2000b. 6-Hydroxyluteolin-7-O-(1"- $\alpha$-rhamnoside) from Vriesea sanguinolenta Cogn. and Marchal (Bromeliaceae). Phytochemistry, 53(8): 965-969.

Chanphen, R., Thebtaranonth, Y., Wanauppathamkul, S. \& Yuthavong, Y. 1998 Antimalarial principles from Artemisia indica. Journal of natural products, 61(9): 1146-1147.

Chen, M., Theander, T.G., Christensen, S.B., Hviid, L., Zhai, L. \& Kharazmi, A. 1994. Licochalcone A, a new antimalarial agent, inhibits in vitro growth of the human malaria parasite Plasmodium falciparum and protects mice from P. yoelii infection. Antimicrobial agents and chemotherapy, 38(7) $1470-1475$.

Darkin-Rattray, S.J., Gurnett, A.M., Myers, R.W., Dulski, P.M., Crumley, T.M \& Allocco, J.J. n.d. 693 Cannova C, Meinke PT, Colletti SL, Bednarek MA, Singh SB, Goetz MA, 694 Dombrowski AW, Polishook JD, Schmatz DM. 1996. Apicidin: a novel antiprotozoal 695 agent that inhibits parasite histone deacetylase. Proc Natl Acad Sci USA, 93: 13143-13696.

Elford, B.C. 1986. L-Glutamine influx in malaria-infected erythrocytes: a target for antimalarials? Parasitology Today, 2(11): 309-312.

Figueiredo, J.N., Räz, B. \& Séquin, U. 1998. Novel quinone methides from Salacia kraussii with in vitro antimalarial activity. Journal of Natural Products, 61(6): 718-723.

François, G., Passreiter, C.M., Woerdenbag, H.J. \& Van Looveren, M. 1996. Antiplasmodial activities and cytotoxic effects of aqueous extracts and sesquiterpene lactones from Neurolaena lobata. Planta medica, 62(02): $126-129$.

Frédérich, M., Cristino, A., Choi, Y.H., Verpoorte, R., Tits, M., Angenot, L., Prost, E., Nuzillard, J.-M. \& Zèches-Hanrot, M. 2004. Chrysopentamine an antiplasmodial anhydronium base from Strychnos usambarensis leaves. Planta medica, 70(1): 72-76.

Frederich, M., De Pauw, M.-C., Llabres, G., Tits, M., Hayette, M.-P., Brandt, V., Penelle, J., De Mol, P. \& Angenot, L. 2000. New antimalarial and cytotoxic sungucine derivatives from Strychnos icaja roots. Planta medica, 66(03): 262-269.

Ghosh, J.K., Shaool, D., Guillaud, P., Cicéron, L., Mazier, D., Kustanovich, I., Shai, Y. \& Mor, A. 1997. Selective Cytotoxicity of Dermaseptin S3 toward IntraerythrocyticPlasmodium falciparum and the Underlying Molecular Basis. Journal of Biological Chemistry, 272(50): 3160931616.

Hallock, Y.F., Cardellina, J.H., Schäffer, M., Bringmann, G., François, G. \& Boyd, M.R. 1998. Korundamine A, a novel HIV-inhibitory and antimalarial "hybrid" naphthylisoquinoline alkaloid heterodimer from Ancistrocladus korupensis. Bioorganic \& Medicinal Chemistry Letters, 8(13): 1729-1734.

Hallock, Y.F., Manfredi, K.P., Dai, J.-R., Cardellina, J.H., Gulakowski, R.J., McMahon, J.B., Schäffer, M., Stahl, M., Gulden, K.-P., Bringmann, G., François, G. \& Boyd, M.R. 1997. Michellamines D-F, New HIV Inhibitory Dimeric Naphthylisoquinoline Alkaloids, and Korupensamine E, a New Antimalarial Monomer, from Ancistrocladus korupensis Journal of Natural Products, 60(7): 677-683.

Hay, A.-E., Ioset, J.-R., Ahua, K.M., Diallo, D., Brun, R. \& Hostettmann, K. 2007. Limonoid orthoacetates and antiprotozoal compounds from the roots of Pseudocedrela kotschyi. Journal of natural products, 70(1): 9-13.

Ichino, C., Kiyohara, H., Soonthornchareonnon, N., Chuakul, W., Ishiyama, A., Sekiguchi, H., Namatame, M., Otoguro, K., Omura, S. \& Yamada, H 2006. Antimalarial activity of biflavonoids from Ochna integerrima. Planta medica, 72(07): 611-614.

Jenett-Siems, K., Siems, K., Jakupovic, J., Solis, P.N., Gupta, M.P., Mockenhaupt, F.P., Bienzle, U. \& Eich, E. 2000. Sipandinolide: a butenolide including a novel type of carbon skeleton from Siparuna andina. Planta medica, 66(04): 384-385.

Karioti, A., Skaltsa, H., Zhang, X., Tonge, P.J., Perozzo, R., Kaiser, M., Franzblau, S.G. \& Tasdemir, D. 2008. Inhibiting enoyl-ACP reductase 
(FabI) across pathogenic microorganisms by linear sesquiterpene lactones from Anthemis auriculata. Phytomedicine, 15(12): 1125-1129.

Kenmogne, M., Prost, E., Harakat, D., Jacquier, M.-J., Frédérich, M., Sondengam, L.B., Zeches, M. \& Waffo-Téguo, P. 2006. Five labdane diterpenoids from the seeds of Aframomum zambesiacum. Phytochemistry, 67(5): 433-438.

Kirmizibekmez, H., Calis, I., Perozzo, R., Brun, R., Donmez, A.A., Linden, A., Rudi, P. \& Tasdemir, D. 2004. Inhibiting activities of the secondary metabolites of Phlomis brunneogaleata against parasitic protozoa and plasmodial enoyl-ACP reductase, a crucial enzyme in fatty acid biosynthesis. Planta medica, 70(8): 711-717.

Klayman, D.L. 1985. Qinghaosu (artemisinin): an antimalarial drug from China. Science, 228(4703): 1049 LP-1055.

Köhler, I., Jenett-Siems, K., Mockenhaupt, F.P., Siems, K., Jakupovic, J., González, J.C., Marco, A., Hernández, R., Ibarra, W.A. \& Berendsohn, U.G. 2001. In vitro antiplasmodial activity of 4-phenylcoumarins from Exostema mexicanum. Planta medica, 67(01): 89-91.

Kraft, C., Jenett-Siems, K., Siems, K., Gupta, M.P., Bienzle, U. \& Eich, E. 2000. Antiplasmodial activity of isoflavones from Andira inermis. Journal of ethnopharmacology, 73(1-2): 131-135.

Krief, S., Martin, M.-T., Grellier, P., Kasenene, J. \& Sévenet, T. 2004. Novel antimalarial compounds isolated in a survey of self-medicative behavior of wild chimpanzees in Uganda. Antimicrobial agents and chemotherapy, 48(8): 3196-3199.

Kuo, P.-C., Damu, A.G., Lee, K.-H. \& Wu, T.-S. 2004. Cytotoxic and antimalarial constituents from the roots of Eurycoma longifolia. Bioorganic \& medicinal chemistry, 12(3): 537-544.

Likhitwitayawuid, K., Phadungcharoen, T. \& Krungkrai, J. 1998. Antimalarial xanthones from Garcinia cowa. Planta medica, 64(01): 70-72.

Limmatvapirat, C., Sirisopanaporn, S. \& Kittakoop, P. 2004. Antitubercular and antiplasmodial constituents of Abrus precatorius. Planta medica, 70(3): 276-278.

Ma, C., Zhang, H.J., Tan, G.T., Hung, N. Van, Cuong, N.M., Soejarto, D.D. \& Fong, H.H.S. 2006. Antimalarial compounds from Grewia bilamellata. Journal of natural products, 69(3): 346-350.

Mambu, L., Grellier, P., Florent, L., Joyeau, R., Ramanitrahasimbola, D., Rasoanaivo, P. \& Frappier, F. 2006. Clerodane and labdane diterpenoids from Nuxia sphaerocephala. Phytochemistry, 67(5): 444-451.

Mambu, L., Martin, M.-T., Razafimahefa, D., Ramanitrahasimbola, D. Rasoanaivo, P. \& Frappier, F. 2000. Spectral characterisation and antiplasmodial activity of bisbenzylisoquinolines from Isolona ghesquiereina. Planta medica, 66(06): 537-540.

Mbwambo, Z.H., Kapingu, M.C., Moshi, M.J., Machumi, F., Apers, S., Cos, P., Ferreira, D., Marais, J.P.J., Vanden Berghe, D. \& Maes, L. 2006. Antiparasitic activity of some xanthones and biflavonoids from the roo bark of Garcinia livingstonei. Journal of natural products, 69(3): 369372.

Muhammad, I., Bedir, E., Khan, S.I., Tekwani, B.L., Khan, I.A., Takamatsu, S., Pelletier, J. \& Walker, L.A. 2004. A New Antimalarial Quassinoid from Simaba o rinocensis. Journal of Natural Products, 67(5): 772-777.

Nilanonta, C., Isaka, M., Kittakoop, P., Palittapongarnpim, P., Kamchonwongpaisan, S., Pittayakhajonwut, D., Tanticharoen, M. \& Thebtaranonth, Y. 2000. Antimycobacterial and antiplasmodial cyclodepsipeptides from the insect pathogenic fungus Paecilomyces tenuipes BCC 1614. Planta medica, 66(08): 756-758.

Nunome, S., Ishiyama, A., Kobayashi, M., Otoguro, K., Kiyohara, H., Yamada, H. \& Omura, S. 2004. In vitro antimalarial activity of biflavonoids from Wikstroemia indica. Planta medica, 70(01): 76-78.

Oketch-Rabah, H.A., Dossaji, S.F., Christensen, S.B., Frydenvang, K., Lemmich, E., Cornett, C., Olsen, C.E., Chen, M., Kharazmi, A. \& Theander, T. 1997. Antiprotozoal compounds from Asparagus africanus. Journal of natural products, 60(10): 1017-1022.

Okunade, A.L., Bikoff, R.E., Casper, S.J., Oksman, A., Goldberg, D.E. \& Lewis, W.H. 2003. Antiplasmodial activity of extracts and quassinoids isolated from seedlings of Ailanthus altissima (Simaroubaceae). Phytotherapy Research, 17(6): 675-677.

Paulo, A., Gomes, E.T., Steele, J., Warhurst, D.C. \& Houghton, P.J. 2000. Antiplasmodial activity of Cryptolepis sanguinolenta alkaloids from leaves and roots. Planta Medica, 66(1): 30-34.

del Rayo Camacho, M., Mata, R., Castaneda, P., Kirby, G.C., Warhurst, D.C., Croft, S.L. \& Phillipson, J.D. 2000. Bioactive compounds from Celaenodendron mexicanum. Planta medica, 66(05): 463-468.

Riel, M.A., Kyle, D.E. \& Milhous, W.K. 2002. Efficacy of scopadulcic acid A against Plasmodium falciparum in vitro. Journal of natural products, 65(4): 614-615

Rochanakij, S., Thebtaranonth, Y., Yenjai, C. \& Yuthavong, Y. 1985. Nimbolide, a constituent of Azadirachta indica, inhibits Plasmodium falciparum in culture. The Southeast Asian journal of tropical medicine and public health, 16(1): 66-72.

Saewan, N., Sutherland, J.D. \& Chantrapromma, K. 2006. Antimalarial tetranortriterpenoids from the seeds of Lansium domesticum Corr. Phytochemistry, 67(20): 2288-2293.

Sawadjoon, S., Kittakoop, P., Isaka, M., Kirtikara, K., Madla, S. \&
Thebtaranonth, Y. 2004. Antiviral and antiplasmodial spirodihydrobenzofuran terpenes from the fungus Stachybotrys nephrospora. Planta medica, 70(11): 1085-1087.

Sharma, S.K., Parasuraman, P., Kumar, G., Surolia, N. \& Surolia, A. 2007. Green tea catechins potentiate triclosan binding to enoyl-ACP reductase from Plasmodium falciparum (PfENR). Journal of medicinal chemistry, 50(4) 765-775.

Silva, L.F.R. e, Lima, E.S., de Vasconcellos, M.C., Aranha, E.S.P., Costa, D.S. Mustafa, E.V., de Morais, S.K.R., Alecrim, M. das G.C., Nunomura, S.M., Struwe, L., de Andrade-Neto, V.F. \& Pohlit, A.M. 2013. In vitro and in vivo antimalarial activity and cytotoxicity of extracts, fractions and a substance isolated from the Amazonian plant Tachia grandiflora (Gentianaceae). Memórias do Instituto Oswaldo Cruz, 108(4): 501-507.

Snow, R.W., Guerra, C.A., Noor, A.M., Myint, H.Y. \& Hay, S.I. 2005. The global distribution of clinical episodes of Plasmodium falciparum malaria. Nature, 434(7030): 214-217.

Tansuwan, S., Pornpakakul, S., Roengsumran, S., Petsom, A., Muangsin, N., Sihanonta, P. \& Chaichit, N. 2007. Antimalarial benzoquinones from an endophytic fungus, Xylaria sp. Journal of natural products, 70(10): 1620 1623

Tasdemir, D., Güner, N.D., Perozzo, R., Brun, R., Dönmez, A.A., Çalıs, I. \& Rüedi, P. 2005. Anti-protozoal and plasmodial FabI enzyme inhibiting metabolites of Scrophularia lepidota roots. Phytochemistry, 66(3): 355362.

Thiem, D.A., Sneden, A.T., Khan, S.I. \& Tekwani, B.L. 2005. Bisnortriterpenes from Salacia m adagascariensis. Journal of natural products, 68(2): $251-$ 254.

Torres-Mendoza, D., González, J., Ortega-Barría, E., Heller, M. V, Capson, T.L., McPhail, K., Gerwick, W.H. \& Cubilla-Rios, L. 2006. Weakly Antimalarial Flavonol Arabinofuranosides from Calycolpus w arszewiczianus. Journal of natural products, 69(5): 826-828.

Traore, F., Faure, R., Ollivier, E., Gasquet, M., Azas, N., Debrauwer, L., Keita, A., Timon-David, P. \& Balansard, G. 2000. Structure and antiprotozoal activity of triterpenoid saponins from Glinus oppositifolius. Planta Medica, 66(04): 368-371.

Uys, A.C.U., Malan, S.F., van Dyk, S. \& van Zyl, R.L. 2002. Antimalarial compounds from Parinari capensis. Bioorganic \& medicinal chemistry letters, 12(16): 2167-2169.

Wilairatana, P., Krudsood, S., Treeprasertsuk, S., Chalermrut, K. \& Looareesuwan, S. 2002. The Future Outlook of Antimalarial Drugs and Recent Work on the Treatment of Malaria. Archives of Medical Research 33(4): 416-421.

Wright, C.W. 2005. Plant Derived Antimalarial Agents: New Leads and Challenges. Phytochemistry Reviews, 4(1): 55-61.

Yenesew, A., Induli, M., Derese, S., Midiwo, J.O., Heydenreich, M., Peter, M.G. Akala, H., Wangui, J., Liyala, P. \& Waters, N.C. 2004. Anti-plasmodial flavonoids from the stem bark of Erythrina abyssinica. Phytochemistry, 65(22): 3029-3032. 